\title{
o desenho na formação do profissional professor
}

\author{
Márcia Moreno (Unochapecó/Udesc)
}

\begin{abstract}
RESUMO
Partindo do pressuposto de que o desenho sempre trouxe apreensões no processo de ensino-aprendizagem, por estar associado à "técnica", domínio e treino, objetivo, com este artigo, propor, por meio da descrição de um experienciar, uma alternativa criativa quanto ao ensino do desenho, de forma a contribuir na/para formação do professor. Nesse compartilhar de uma realização do curso de formação superior em Artes Visuais-licenciatura, o desenho entra tanto como entremeio de um processo, quanto em paralelo à pesquisa sobre anomalias de nascença ou adquiridas, contrapondo o conceito de belo estético que muitas vezes tem como característica essencial do percurso. Ainda, teço considerações teóricas sobre o espaço escolar, sobre - professor e seu protagonismo nas relações científicas e sociais na formação do sujeito, bem como sobre a contribuição significativa que essa linguagem tem para a percepção, reflexão e criatividade na relação alunorealidade-arte.
\end{abstract}

PALAVRAS CHAVE: Desenho; Criatividade; Escola.

\section{ABSTRACT}

Assuming that drawing has always brought apprehension in the teachinglearning process, as it is associated with the "technique", mastery and training, the objective of this article is to propose, through the description of an experience, a creative alternative to the teaching of drawing in order to contribute to/for teacher's education. Through sharing a realization of the degree in Visual Arts, drawing enters both as a process intertwining, and in parallel with research on birth or acquired anomalies, contrasting the concept of beauty aesthetic that is often characterized by the essential route. Still, I make theoretical considerations about the school space, about the teacher and its role in the scientific and social relations in the subject's formation, as well as about the significant contribution that this language can to the perception, reflection, and creativity in the student-reality-art relationship.

KEYWORDS: Drawing; Creativity; School.

\section{O DESENHO NA FORMAÇÃO DO PROFESSOR: uma breve discussão}

O desenho sempre foi um impasse para muitos que tentam se aproximar das Artes Visuais. Nós, como educadores e formadores, durante os tempos/momentos de criar, ouvimos afirmações tais 


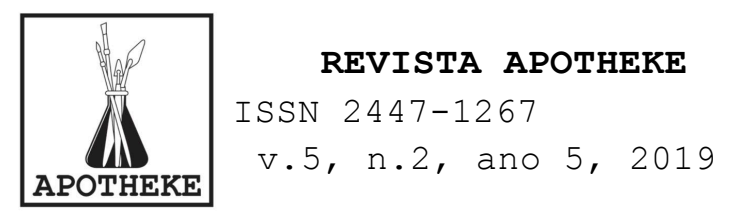

como "eu não sei desenhar!" e, com isso, ocorre um afastamento dessa linguagem, que passa a ser temida, principalmente, na fase adulta.

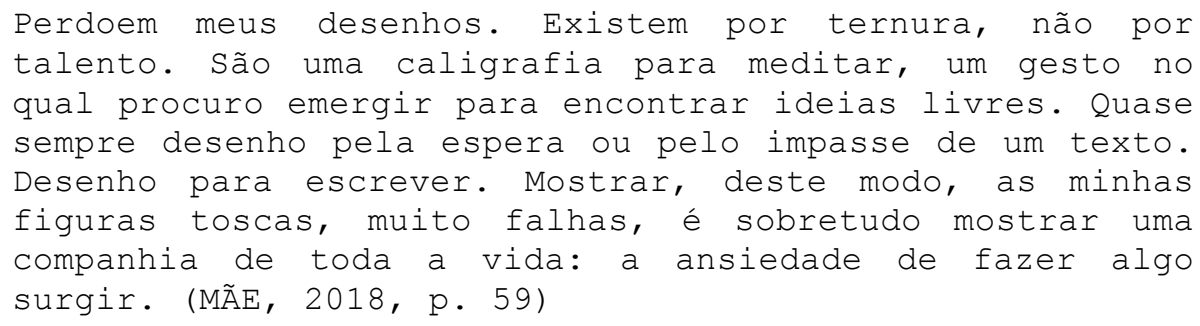

Nesse excerto, o autor desculpa-se pelo seu traço, afirmando que o que importa a ele não é o desenho, sua qualidade, mas sim o que ele expõe, o que ele externaliza através do desenho, sem intenção de qualidade técnica e estética.

A citação acima, do autor Mãe (2018), reforçou o que eu vinha questionando quanto à "qualificação" desse profissional do ensino, aquele que é formado por cursos de licenciatura. Entendo que o curto tempo destinado à compreensão e ao processo do domínio do desenho impossibilita-lhe a capacitação para esse ensino; e mais, dele se distancia a concepção de que tal aprendizado, no ensino básico, possa se dar de forma prazerosa e com qualidade.

Cox (2001) afirma que, na fase adulta, assumir que não se sabe desenhar é tão difícil quanto o ato de desenhar; diante disso, recuperamos o quanto ouvimos nossos (e outros) alunos dizerem que não gostam, que não têm o "dom", que preferem outra linguagem à do desenho, etc. Dentro dessa questão, como amenizar, minimamente que seja, esse sentimento de repulsa pelo desenho?

Nas escolas, o professor habilitado em Artes Visuais precisa atuar, mas, quando muito, teve três semestres do componente que trata sobre o desenho. Sabe-se que, para ser um profissional do desenho, assim como qualquer outro experto, há a necessidade de muitos anos de estudos e de experienciações. 


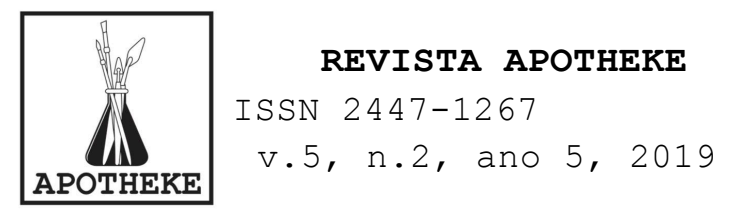

Então, como exigir que o professor do ensino básico tenha qualificações suficientes para trabalhar essa linguagem na escola, de forma a estimular a criança?

Há que considerar, no entanto, que existem, nas instituições de ensino superior, professores artistas, sujeitos que têm uma longa trajetória na formação do desenho (ensino complementar em espaço não formal), que podem, por sua vez, oferecer subsídios a esses futuros professores para que possam ter uma melhor atuação em sala de aula, no sentido de possibilitar significativas e exitosas experiências aos seus alunos do ensino básico.

A partir do exposto, o desafio é justamente propor, experienciar possibilidades de trabalhar com 0 ensino do desenho na formação desse professor que irá para a escola, de maneira a contribuir, de forma criativa, com alternativas para com o uso do desenho. A experiência vivenciada, no decorrer de 17 anos na docência do ensino superior, levou-me a vários questionamentos e distintos entendimentos. Os questionamentos se dão, principalmente, em relação ao precário processo de ensino aprendizagem do ensino das Artes Visuais nas escolas, tendo o desenho como linguagem, onde, segundo Barbosa (2015), ainda prevalece o desenho "livre", o que não só bloqueia como também limita a capacidade cognitiva, criativa e reflexiva do sujeito.

Essa deficiência pode ser evidenciada na vida adulta do sujeito, impossibilitando, muitas vezes, o desenvolvimento da sua capacidade cognitiva, tornando-o um ser que apenas reproduz o que vê e não produz conhecimento reflexivo. A proposição da experiência que aqui será exposta foi desenvolvida num curso superior de formação em Artes Visuais - Licenciatura, quando deixamos de abordar a técnica pela técnica, tratando o desenho como um entremeio da diligência, sem que se constituísse como a 


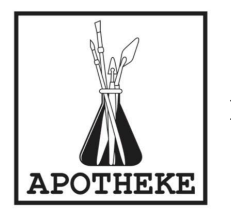

REVISTA APOTHEKE

ISSN 2447-1267

v.5, n.2, ano 5, 2019

linguagem principal - uma vez que o inverso, muitas vezes, acaba por intimidar o processo criativo do aluno.

\section{O PROCESSO DE ENSINO DE ARTES VISUAIS TENDO O DESENHO COMO ENTREMEIO}

O ensino do desenho é um desafio, ainda mais quando se aborda a formação de professores na licenciatura em Artes Visuais. O pouco tempo para aprofundar e exercitar essa linguagem reflete-se na forma como é usada - equivocada, ou, até mesmo, erroneamente - nas escolas. Para tanto, cabe ao professor formador desenvolver maneiras de amenizar esses "desfalques" quanto ao uso da linguagem do desenho no espaço escolar. Em outras palavras, cabe ao professor formador ter contato com diferentes modos de experienciar e compartilhar o uso do desenho, sem discriminar, tampouco vulgarizar o processo; ao contrário, com vistas a instigar a criatividade do futuro professor do ensino básico.

A partir do exposto, trarei aqui, mesmo que brevemente, uma atividade desenvolvida em um curso de ensino superior de Artes Visuais - Licenciatura, no componente de desenho, o qual teve, como propósito, em sua ementa, o desenho da figura humana, tema que muito impacta os alunos, pois creditam a esse aprendizado ser complexo e dificultoso. Deve-se considerar que esses alunos já tiveram dois semestres de desenho, o que lhes permite um discernimento razoável sobre o assunto.

A proposição da atividade para com essa turma foi paradoxal com o que até então havia sido trabalhado. A ideia partiu do uso de referências de imagens de pessoas que apresentassem algum tipo de anomalia, de nascença ou adquirida, - que os distanciaria de estereótipos de beleza estética, bem como da preocupação no que concerne à qualidade do desenho dito/pensado realista. 


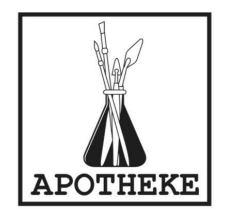

REVISTA APOTHEKE

ISSN 2447-1267

v.5, n.2, ano 5, 2019

Além do tema proposto para explorar o desenho de criação, a saber, "a figura humana e anomalias", o aluno deveria utilizar embalagens de papel pardo, quantas achasse necessárias ao trabalho. Essa proposição foi mais um artifício para que o desenho enquanto técnica não fosse o foco principal, justamente para não "bloquear" o processo de criação. Antes de qualquer início de estudos, os alunos tiveram uma explanação sobre processos de criação, cujos autores de referência foram Eunice de Alencar, Howard Gardner, Tai Hsuan-An, Fayga Ostrower, Analice Pillar, entre outros.

Para Ostrower(2014), no âmbito conceitual ou intelectual, os processos criativos articulam-se, principalmente, através da sensibilidade, sendo ela patrimônio de todos os seres humanos, ainda que em áreas sensíveis diferentes. No entanto, Gardner (1999) afirma que todo ser humano nasce com um potencial de sensibilidade, que é um canal ou porta de entrada das sensações, ligando-nos, de imediato, a tudo aquilo que acontece ao nosso entorno; mas, para tal desenvolvimento, é de suma importância os estímulos proporcionados ao sujeito e por ele vivenciados.

Ao se analisar a criatividade em artistas e em cientistas - a considerar que, neles, essa se apresenta mais evidente -, verificou-se, segundo Gardner (1999), que ela não se constitui como resultado de uma inspiração súbita, mas sim de muito trabalho e esforço por parte do indivíduo. Com base nisso, para instigar a criatividade, existem vários processos que visam a remover as barreiras que inibem ou que bloqueiam essa manifestação em sujeitos que tiveram menos estímulos.

A atividade proposta para os alunos, futuros professores do ensino básico, partiu da teoria sobre a criatividade, para então serem instigados para o processo de criação, tendo como tema para o desenvolvimento da atividade, conforme já referido, "a figura humana e anomalias". 


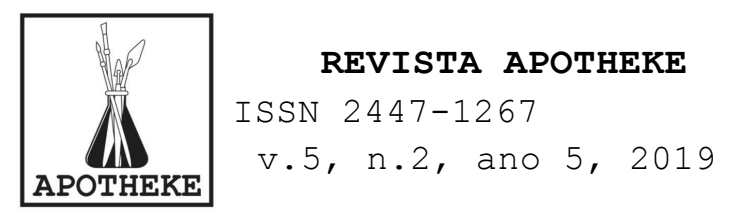

Após as discussões referente à criatividade e aos seus processos, o aluno tinha liberdade para escolher uma figura humana que apresentasse algum tipo de anomalia, podendo ser ela de nascença ou adquirida. Além dessa pesquisa, deveria contrapor, com um artista, a estética visual, e, com um filósofo, o tema, ponderando os assuntos pertinentes à proposta definida anteriormente.

Dewey (2010) comenta, em seu livro "Arte e Experiência", que é exatamente ela, a experiência, que, durante o processo, deve ser plena. Para ele, "é esse grau de completude do viver, na experiência de fazer e perceber, que estabelece a diferença entre o que é belo ou estético na arte e o que não é" (DEWEY, 2010, p.96). Nisso consiste a importância em se pesquisar um teórico que aborda a estética vinculado ao belo, para compreender as concepções e argumentar sobre elas no momento da socialização, o que também colabora para a ampliação do repertório teórico de todos.

Trarei aqui duas de algumas anomalias pesquisadas pelos alunos durante as aulas, em que 0 desenho funciona como entremeio para o processo de criação; são elas a mastectomia e a deformação congênita dos pés.

A primeira refere-se à anomalia resultante de cirurgia da mama feminina após constatação de câncer. A aluna Taise Z. M.² pesquisou sobre a atitude/comportamento de algumas mulheres que haviam retirado as mamas, mas optaram por não as "restaurarem", deixando apenas suas cicatrizes; outras, por opção, "restauraram" a mama, mas não inseriram o mamilo, adquirindo adesivos como uma forma de evitar mais uma cirurgia, ou, até mesmo, o uso de tatuagens permanentes (há tatuadores especializados em reprodução de mamilos e aréolas).

Como referência visual, Taise trouxe Aniela McGuinness,

2 As alunas aqui citadas autorizaram 0 uso de seus nomes e imagens dos trabalhos realizados em sala de aula. 


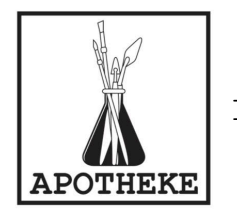

REVISTA APOTHEKE

ISSN 2447-1267

v.5, n.2, ano 5, 2019

uma atriz americana que, ao descobrir o câncer de mama, submeteu-se à mastectomia das duas mamas. Como é uma figura pública, realizou um ensaio fotográfico no qual registrou, de forma irônica e instigante, as sensações vividas após o procedimento. As imagens fazem relação com o personagem de Frankenstein e com a boneca Barbie; nessa última, ela se compara à boneca, pois seus seios estão sem mamilos, assim como os da boneca. Aniela argumentou, em seu blog, que optou por não reconstituílos em função dos procedimentos dolorosos e opta por adesivos; foi a partir daí que a aluna Taise Z. M. inicia a proposição da sua criação.

Abaixo, trago o início de seus estudos, bem como o resultado da pesquisa visual de maneira interativa. Sua intenção era a de que, além de apresentar e aproximar uma realidade vivenciada por muitas mulheres, as pessoas pudessem interagir com os seus desenhos.
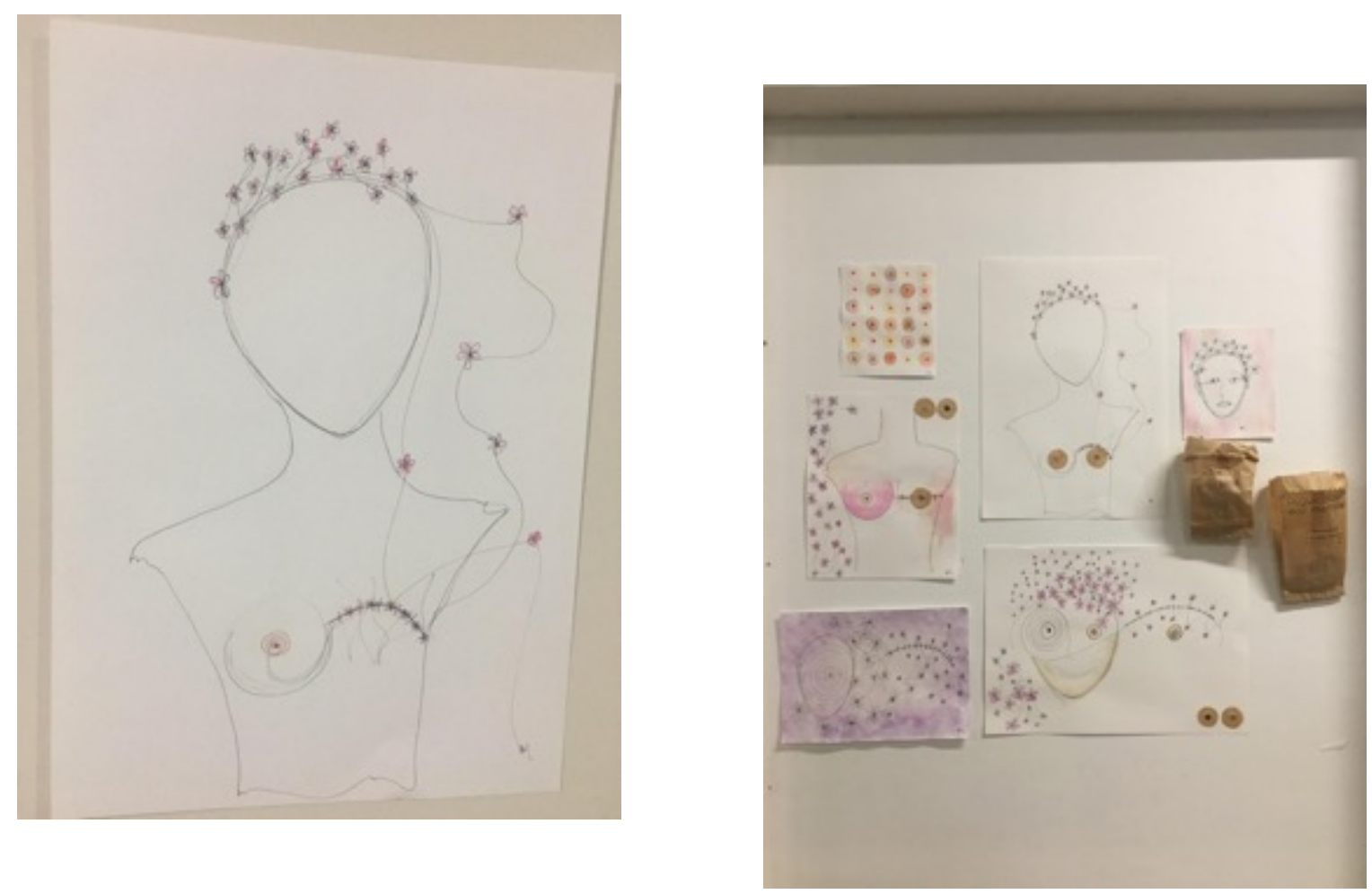


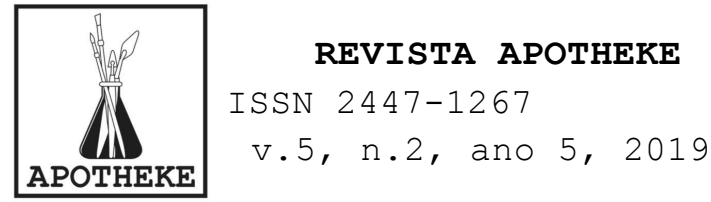

Figuras 1 e 2: Estudos e disposição do trabalho da Taise Z. M. na integra.

Fonte: Taise Z. M., 2019.
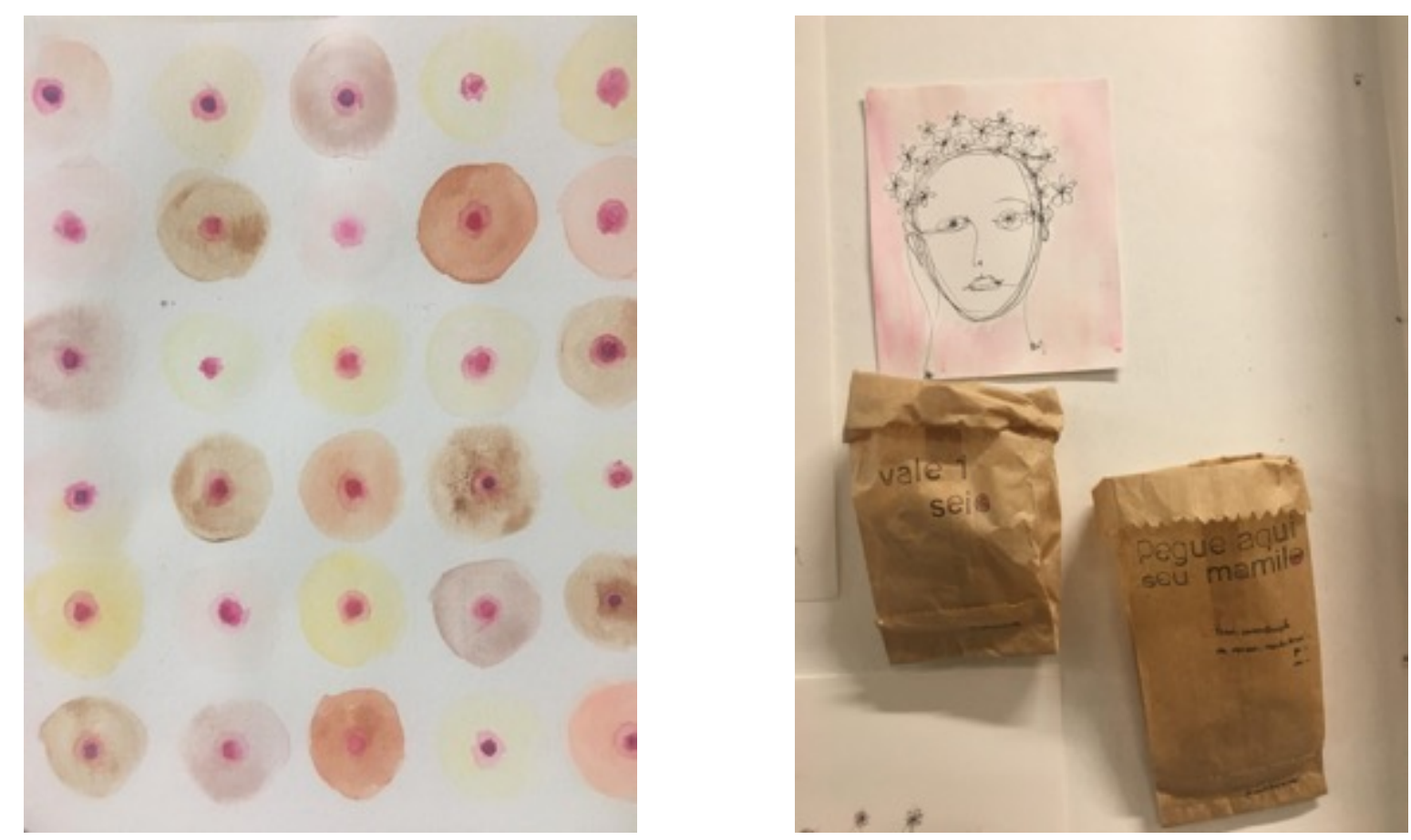

Figuras 3 e 4: Detalhe dos estudos.

Fonte: Taise Z. M., 2019.

Essa atividade proposta aos alunos, futuros professores do ensino básico, foi a partir de diálogos referentes às dificuldades que têm em dominar o desenho da figura humana e até que ponto há a necessidade de tal abordagem para trabalhar nas escolas. Além disso, deve-se considerar o curto tempo dedicado ao desenho nas matrizes das licenciaturas, o que dificulta o processo de ensino aprendizagem do uso do desenho enquanto linguagem.

Para tanto, trago a autora Iavelberg (2013), que afirma que "[...] todos podem desenhar e todos podem aprender a ensinar a desenhar; basta atentar para teorias e práticas 


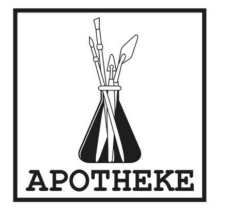

REVISTA APOTHEKE

ISSN 2447-1267

v.5, n.2, ano 5, 2019

coerentes com as boas proposições sobre a aprendizagem do desenho na educação infantil." (IAVELBERG, 2013, p.31). Mas, para isso, o "profissional" do ensino, como cita Jesus (2013), deve ter uma trajetória para tal, ele deve permitir-se a essa experiência entre a prática e a teoria antes de compartilhar, de propor atividades coerentes na escola.

Quanto à aluna Eliana T. dos S., optou por abordar "deformação congênita dos pés". Ela trouxe, para os colegas, que essa malformação é genética, exemplificou com vários casos e discorreu sobre a estética visual que essa doença apresenta. Como o proposto previamente, a atividade deveria contemplar, além da pesquisa visual, a teórica, tendo, como orientação, um artista e um teórico. Para isso, a aluna Eliana T. dos S. pesquisou sobre Pablo Picasso e Immanuel Kant; do primeiro, trouxe sua fase cubista como "deformação da figura humana"; do segundo, apresentou o conceito de Belo. Para tal discussão, trago a citação do Jiminez (1999) quanto a esse conceito:

\begin{abstract}
Aparentemente, as coisas seriam mais simples se existisse um conceito de belo, ligado a uma regra ou a uma lei universal. Para convencer os outros a partilhar meu sentimento, bastar-me-ia demonstrarlhes racionalmente, por exemplo, que este poema ou este edifício são belos. Caso em que, aliás, não teríamos mais, nem eles nem eu, necessidade de julgar; bastaria curvar-se diante de razões objetivas. Mas justamente, não existe nenhuma prova a priori capaz de impor a alguém os juízos de gosto. (JIMENEZ, 1999, p.122)
\end{abstract}

Se houvesse um conceito de belo, esse se haveria/apresentaria como uma lógica, não como uma estética; porém, sem esse conceito de belo, uma ciência a ele relacionada seria impossível; dessa forma, pode-se então elaborar uma estética do juízo do gosto. Kant nos apresenta também a beleza artística (realizações humanas) e a natural (seres vivos), afirmando que o belo basta-se a si mesmo e que não é preciso desejar embelezá-lo; além disso, cita, como exemplos, a 


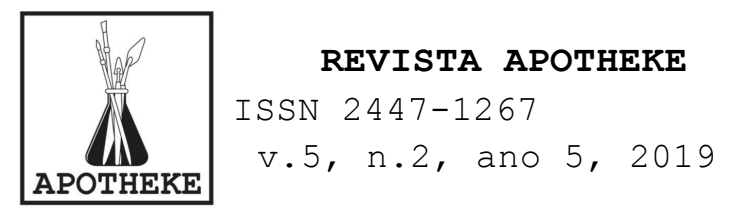

pintura, a escultura, a arquitetura e a arte dos jardins. O belo é dado ao artístico e ao natural, estabelecido diferentemente por cada sujeito que o aprecia.

Com isso posto, explicito que o intuito era apresentar ao aluno essa contraposição: que, no belo estético, não impera o processo que corresponde ao esperado pelo espectador. Em um desenho, esperam-se outras questões de maneira a questionar, refletir, comunicar sobre algo. Percebo, nesse processo, que muitos alunos estão aprisionados ao modelo clássico do ensino do desenho, onde o resultado deve ser similar ao real, o que torna esta linguagem como uma mera técnica. Para tal afirmação, trago Dewey (2010), quando diz: "[...] sem a emoção, pode haver habilidade artística, mas não arte; ela pode estar presente e ser intensa, mas, se for diretamente manifestada, o resultado também não será arte" (DEWEY, 2010, p.160).

A técnica pela técnica não traz a subjetividade, a pesquisa, a linguagem, a comunicação de algo, apenas pretende provar ao outro a sua capacidade de domínio. Mas, do que tudo isso valerá sem a espontaneidade do processo? Para responder a isso, o autor ainda complementa "[...] a 'espontaneidade' resulta de longos períodos de atividade, ou então é tão vazia que não constitui um ato expressivo"(DEWEY, 2010, p.165) .

Deve-se organizar o ensino das Artes Visuais de maneira reflexiva, tanto na formação desse profissional do ensino básico, quanto ele próprio no campo escolar. Só é possível compartilhar aquilo que se experiencia; caso contrário, será algo raso, superficial. Contudo, vejo que nas escolas, muitas vezes, se trabalha de forma que "tudo pode", "tudo é possível" no campo das Artes Visuais. Para pensar tal questão, cito Duve (2011), que traz algo muito pertinente: "[...] o fato de podermos fazer arte com qualquer coisa significa que o velho sistema das belas-artes está morto e enterrado. [...] Como preparar os estudantes para enfrentar esta liberdade 


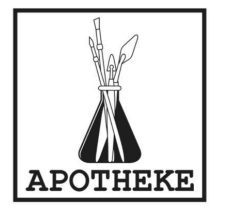

REVISTA APOTHEKE

ISSN 2447-1267

v.5, n.2, ano 5, 2019

assustadora de modo crítico e criativo, sem se perder?"(DUVE, 2011, p. 296-297).

A orientação de uma boa formação é essencial, mas isso não garante que esse aluno será um bom profissional do ensino das Artes Visuais. Nesse sentido, Torrance (apud Alencar, 1993) comenta que o professor deve incentivar a criatividade de seus alunos, mas acredita que não há uma garantia de que criança criativa venha a ser um adulto criativo. Mesmo assim, deve-o fazer. Para Hsuan An (1997), o indivíduo é criativo porque é "[...]capaz de perceber, compreender, relacionar, generalizar, interpretar, explicar, analisar, sintetizar e fundamentalmente expressar" (HSUAN AN, 1997, p.17), e ele cria porque necessita dessa ação.

A liberação da criatividade é dada através do trabalho prático experimental, em paralelo com a investigação teórica. O sujeito, sempre que solicitado a desempenhar um desenho de criação, irá usufruir das informações visuais já adquiridas no decorrer de suas experiências e vivências, pois:

É necessário que se inspire ou se baseie em alguma coisa (...). como a criatividade é inerente a qualquer pessoa, sua desenvoltura depende de alguns fatores, tais como a desinibição, a vontade, o conhecimento, inclusive de certos princípios da composição técnicas e métodos, porque a criação requer um processo de elaboração[...] (HSUAN AN, 1997, p.38).

Com essas investigações de teóricos e análises referentes ao uso do desenho de forma investigativa e criativa, é que proponho experienciações com os alunos de licenciatura em Artes Visuais. Nesse processo, viso sempre a relacionar a teoria com a prática, de maneira a ampliar o repertório textual e visual dos acadêmicos.

Ao dar continuidade à descrição do trabalho da aluna Eliana T. dos S., que traz a anomalia congênita dos pés, posso afirmar que ela, em sua pesquisa, reflete o belo estético, 


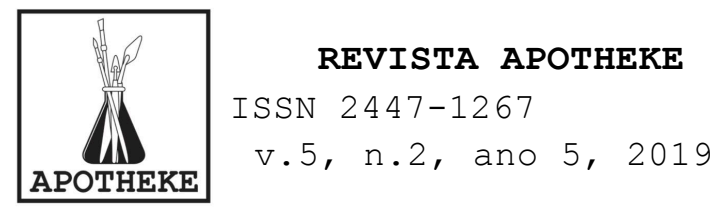

propondo, sobre a imagem trabalhada, ornamentos aplicados, tentando assim atender o exigido por uma sociedade em que certa beleza impera sobre o subjetivo, sobre o eu, sobre o ser. Sua proposição deu-se com a aplicação de pingentes sobre as "unhas", com o intuito de "embelezar" esse pé deformado, dando uma "graciosidade", uma leveza a uma forma tão "grotesca" aos olhos do "Belo". Além dos pingentes, a aluna provoca o espectador ao inserir tiras de chinelo sobre essa imagem, algo que é inviável pela deformidade dos pés, possibilitando, com isso, uma reflexão sobre as normativas de uma sociedade. 
ISSN $2447-1267$

$\mathrm{v} .5, \mathrm{n} .2$, ano 5, 2019
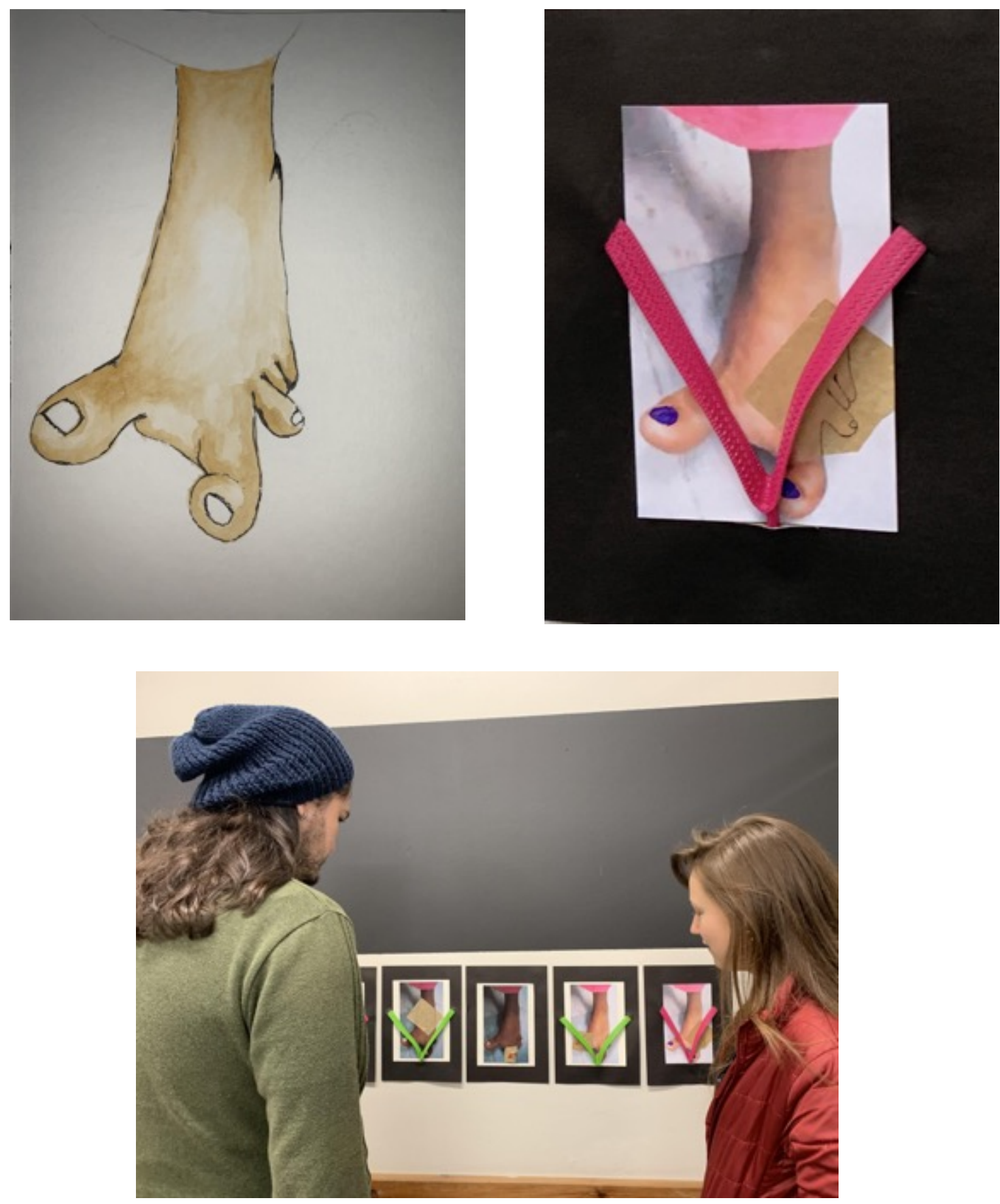

Figuras 5 e 6: Estudos e disposição do trabalho na íntegra da Eliana T. dos S.

Fonte: Eliana T. dos S., 2019.

A aluna Eliana $T$. dos $\mathrm{S}$. também inseriu embalagens de 


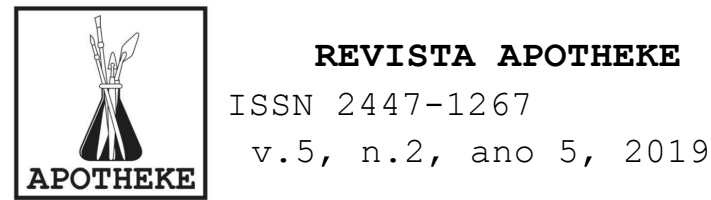

papel pardo (proposto previamente para essa atividade) como suporte para parte do desenho, imerso sobre a imagem impressa em cor. Sobre essa informação visual, além dessa adaptação estético-visual, a aluna agregou as tiras de chinelo de maneira a causar ainda mais estranhamento por parte do espectador, se considerar a impossibilidade de uso decorrente da anomalia congênita.

Partindo do aqui exposto, chego ao ponto essencial deste artigo: o desafio de propor o experienciar possibilidades de ensino de desenho na formação desse professor que irá para a escola e lá trabalhará com crianças/adolescentes. Trouxe aqui apenas um ensaio, uma proposição para esse futuro professor, usar do desenho para trabalhar as diferenças, o respeito, o outro, não pensar o desenho apenas como técnica a ser transferida a uma turma de Artes Visuais.

Dewey (2002) discute em seu livro "A escola e a sociedade: a criança e o currículo" que as formações universitárias "[...] estão isoladas dos conteúdos académicos mais elaborados, uma vez que, acima de tudo, o seu objectivo se tem prendido com a formação relativa a como ensinar e não o que ensinar"; além disso, complementa: "[...] se pensarmos na universidade, encontramos o isolamento diametralmente oposto: a aprendizagem de o que ensinar, com um quase desprezo pelos métodos de ensino"(DEWEY, 2002, p.64). Como também professores, os formadores de professores para o ensino básico não devem se esquecer "da sua própria infância", como cita Dewey. Devemos sim considerar a trajetória intra e interpessoal, o ambiente escolar, sem jamais nos distanciarmos desse universo infantojuvenil.

\section{CONSIDERAÇÕES REFERENTE A UM PROCESSO}


Sei que o que apresentei aqui é apenas um exercício que propus a uma turma em formação docente, na tentativa de desvelar/desfazer/desconstruir o desenho como uma simples técnica. Com isso, penso que o desenho, enquanto linguagem, pode comunicar muito além do estético visual; considero que o professor deve trabalhá-lo de maneira a aproximar-se do universo escolar, por meio da proposição de discussões e da articulação dessas propostas com temáticas relevantes à formação desse sujeito pertencente a esse espaço. Segundo Dewey (2002), a escola deve "[...] assegurar a relação orgânica com a vida social de que temos vindo falar" (DEWEY, 2002, p. 70), e a Arte é um considerável canalizador para tal.

O intuito de trabalhar com o desenho da figura humana de maneira a extrapolar o belo estético, inclusive a própria técnica, possibilita, ao futuro professor do ensino básico, experienciar o desenho para além da técnica. É de suma importância que o professor formador proporcione atividades reflexivas, relacionando-as com o universo escolar, para que não haja distanciamento e/ou esquecimento de uma fase que todos vivenciam, mesmo que com intensidades diferenciadas.

A formação é cíclica e é necessário que se tenha essa convicção. Muitas vezes, o professor está inserido no campo educacional munido de seus conhecimentos científicos, mas desconecto da imersão social dos atuantes no ambiente do ensino básico.

Acredito que os alunos com os quais venho contribuindo, no que concerne à sua formação para atuarem como licenciados, possam desenvolver atividades diferenciadas, utilizando-se, para isso, da área das Artes Visuais e do desenho como propulsores de assuntos/temáticas pertinentes à suas vivências/experiências. Dessa forma, avalio que muito se poderá agregar para com a formação desses sujeitos, tornando-os não somente mais reflexivos e indagadores, mas também - libertos e 
destemidos - mais criativos em suas ações, independentemente da área em que forem atuar na fase adulta.

\section{REFERÊNCIAS BIBLIOGRÁFICAS}

ALENCAR, Eunice M. L. S. Criatividade. Edit. Edunb, Brasília, 1993.

COX, Maureen. Desenho da Criança. São Paulo: Martins Fontes, 2001.

DEWEY, John. A escola e a sociedade e A criança e o Currículo. Lisboa: Relógio D'Água Editores, 2002.

-----. Arte como Experiência. São Paulo: Martins Fontes, 2010.

DUVE, Thierry de. Fazendo escola (ou refazendo-a?). Chapecó: Argos, 2011.

GARDNER, Howard. Arte, mente e cérebro: uma abordagem cognitiva da criatividade. Porto Alegre: Artes Médicas, 1999.

IAVELBERG, Rosa. Desenho na Educação Infantil. São Paulo: Melhoramentos, 2013.

HSUAN-AN, Tai. Desenho e organização bi e tridimensional da forma. Goiânia: UCG, 1997.

JESUS, Joaquim A. Luz. (In)Visibilidades: um estudo sobre o devir do professor-artista no ensino em artes visuais. Tese de doutoramento em Educação Artística, Faculdade de Belas Artes, Porto/Portugal, 2013.

JIMENEZ, Marc. o que é estética. São Leopoldo, Unisinos, 1999.

MÃE, Valter H. Mãe. O Paraíso são os outros. 2 a ed. Rio de Janeiro: Biblioteca azul, 2018.

OSTROWER, Fayga. Criatividade e processos de criação. Petrópolis: Vozes, 2014 .

Endereço eletrônico do lattes: http://lattes.cnpq.br/2033614037398089

Márcia Moreno possui graduação em Desenho e Plástica Bacharel e Licenciatura pela Universidade Federal de Santa Maria - UFSM (2000/2002); Mestrado em Educação pela Universidade Federal de Santa Maria - UFSM (2005) e especialização em Criatividade: arte e tecnologias pela Universidade Comunitária da Região de Chapecó - UNOCHAPECO (2009). Doutoranda em Artes Visuais na Universidade Estadual de Santa Catarina - UDESC (2018). Atuou como docente no ensino superior na Universidade Federal de Santa Maria (professora substituta), na Unoesc (campus Xanxerê, Joaçaba e São Miguel do Oeste) e atualmente é professora titular da Universidade Comunitária da Região de Chapecó - UNOCHAPECó no Curso de Artes Visuais. Coordena a Galeria de Artes Agostinho Duarte (Unochapecó). É coordenadora do Curso de Artes Visuais - licenciatura. Vice líder do grupo de pesquisa: Arte, Visualidade e Cultura (Unochapecó) .

Recebido em 29 de julho de 2019. Aprovado em 18 de agosto de 2019. ORCID: https://orcid.org/0000-0002-6484-0477 